\title{
Picture-word differences and conceptual frequency judgments
}

\author{
JOEL R. LEVIN \\ University of Wisconsin, Madison, Wisconsin 59706 \\ LYLE E. BOURNE, JR. \\ University of Colorado, Boulder, Colorado 80302 \\ R. A. YAROUSH \\ University of Denver, Denver, Colorado 80210 \\ ELIZABETH S. GHATALA \\ Weber State College, Ogden, Utah 84408 \\ THOMAS M. DeROSE \\ University of Wisconsin, Madison, Wisconsin 59706 \\ and \\ VICKI HANSON \\ University of Colorado Boulder, Colorado 80302
}

\begin{abstract}
Recent evidence suggests that while pictures are more easily recognized, discriminated, associated, and recalled than their corresponding verbal labels, this is not the case in concept acquisition/utilization tasks. If such evidence is interpreted in terms of a "frequency theory" perspective, one would expect the typically obtained frequency judgment differences between pictures and words to be reduced if "conceptual" frequency judgments are required. This expectation was confirmed in three experiments.
\end{abstract}

Recent evidence suggests that the superiority of pictorial over verbal stimuli in discrimination learning tasks (cf. Rowe, 1972; Rowe \& Paivio, 1971; Wilder \& Levin, 1973) may be attributable to subjective frequency differences associated with the two types of material. In a series of experiments in which items were presented with varying frequencies (generally from one to five times), we have found that lists consisting of pictures produce frequency judgment performance which differs from that produced by lists consisting of the pictures' verbal labels (Ghatala \&

This research was funded by the Wisconsin Research and Development Center for Cognitive Learning, supported in part as a research and development center by funds from the National Institute of Education (Center No. NE-C-0n-3-0065). The opinions herein do not necessarily reflect the position or policy of the National Institute of Education, and no official endorsement by the National Institute of Education should be inferred. Some of the data reported were collected at the Institute for the Study of Intellectual Behavior. This work was supported in part by a research grant. $M H$ 14314, and by a Research Scientist Award, 1-K5-MH 37497, both from the National Institute of Mental Health; and by a research grant, GB-340.77X, from the National Science Foundation. We are grateful to the staff and students of Dickason School in Columbus, Wisconsin, and to Pamela Brooks for typing the paper. Vicki Hanson is now at the University of Oregon. Reprint requests should be addressed to Joel R. Levin, Wisconsin Research and Development Center for Cognitive Learning. 1025 West Johnson Street, Madison, Wisconsin 53706.
Levin, 1973. 1974; Ghatala. Levin, \& Wilder, 1973). In particular, pictures are consistently judged with less variability and with greater accuracy than words. Theoretically, such picture-word differences in subjective frequency, combined with the tenets of frequency theory (Ekstrand. Wallace. \& Underwood, 1966), should be sufficient to account for picture-word differences in discrimination learning, and, indeed, they are (Levin, Ghatala, \& Wilder, 1974).

In contrast to these results, however, Levin (in press) has concluded that although picture-over-word effects have been repeatedly demonstrated in tasks demanding item recognition, item discrimination, and item recall (cf. Paivio, 1971), this has not been true in tasks involving the formation or utilization of conceptual categories (see, for example, Runquist \& Hutt, 1961). It is possible that the unique perceptible features of a picture. not all of which are relevant to the concept it instantiates, may interfere in some way with the formation of the semantically broader and generally more abstract or inclusive concept.

The three experiments reported here were conducted to determine whether such effects would extend to frequency judgments of categories. That is, even though pictures are more easily recognized and discriminated in comparison to their verbal 
counterparts, does the specificity of pictures or their dominating perceptible features prevent subjective frequency units from generalizing across different category instances of the same category? In Experiments I and II, we utilized narrowly defined base categories, in Rosch's (1973) sense (e.g., BOOT as represented by a cowboy boot and a rain boot), whereas in Experiment III, in an effort to establish the generality of our results, we used concepts which are superordinate to the basic level (e.g., CLOTHING as represented by a shirt and a dress).

\section{EXPERIMENTS I AND II}

\section{Method}

Design and Materials. The design consisted of four experimental conditions as defined by the combination of two types of stimulus materials (pictures vs. words) and two list types (same vs. different).

In the "same"-picture condition, the stimuli were 44 line drawings of familiar objects (e.g.. a rain boot. an alarm clock, a farm house). In the "same"-word condition. the objects" printed verbal labels were used ("rain boot," "alarm clock," "farm house"). In each condition, 34 of the items were randomly distributed among the four frequency levels represented in the study list. The 10 remaining stimuli were used as filler (or zero-frequency) items on the test list. The study list consisted of 16 pictures (or words) presented once, 9 presented twice, 5 presented three times and 4 presented four times, resulting in a total of 65 study presentations. The order of study presentations was random. subject to the restriction that items with multiple occurrences were distributed equally in each equal-sized section, with the number of sections determined by the frequency. Thus. an item presented twice occurred once in each half of the list, an item presented three times appeared in each third of the list. and an item presented four times appeared in each quarter of the list. The same item never appeared in adjacent positions. Of the 16 items occurring once. 4 were randomly assigned to each quarter of the list. The test list consisted of the same 34 items that had appeared on the study lis plus the 10 filler items. The order of test presentations was random.

In the "different" conditions, the stimuli consisted of different instances from the object classes represented in the "same" conditions. That is. for items presented once on the study list, a different instance of the same narrowly defined category appeared on the test list (e.g.. a cowboy boot during study and a rain boot during test). For items presented more than once during study, a different category instance appeared on each study presentation as well as on the test list (e.g., a "two" item consisted of an electric clock and a grandfather clock during study and an alarm clock during test). The order of study and test presentations in the "different" conditions duplicated that of the "same" conditions.

The line drawings were photographed and mounter one to a slide. The word pairs (modified nouns) were typed in primary type, photographed, and mounted one to a slide.

Subjects. In Experiment 1, the subjects were 120 sixth and seventh graders from an elementary school in a semirural Wisconsin community. Within each grade, the subjects were randomly assigned to one of the four experimental conditions. Fifteen sixth and 15 seventh graders were thus assigned to each condition. In Experiment II, the subjects were 48 volunteers from an introductory psychology class at the University of Colorado, who were fulfilling a course requirement. Twelve subjects were randomly assigned to each of the four experimental conditions.

Procedure. All subjects were tested individually, with the slides presented at a 5 -sec rate. All subjects were told that they would be shown several items, some of which would occur more than once, and that they should pay close attention because, later, they would be asked questions about the items. The subjects in the "different" conditions were told that repetitions would consist of different instances of the same category. Moreover, in Experiment II, subjects in the "different" conditions were informed that their subsequent task would be to estimate the number of times each category had been presented (since information obtained in Experiment $I$ and in a subsequent experiment had indicated that the task was too difficult without this additional instruction). A sample item appropriate for each condition was presented prior to administration of the actual list.

After viewing the study list. subjects were given the appropriate test list at the same rate. The subjects were instructed to respond to each item. guessing if uncertain, by saying the nu mber of times that the item (or category, in the case of subjects in the "different" conditions) had previously occurred. They were told that some items (categories) would be presented that they had not seen before. and for these stimuli they were to respond "zero." To help clarify the task, the previous sample item was re-presented.

\section{Results and Discussion}

The dependent variable consisted of the number of exact frequency judgments made by a subject across the 44 test list items-a measure that we have employed previously (e.g., Ghatala \& Levin, 1974). Thus, for example, a response of "two" to an item previously seen twice would be the correct response for subjects in the "same" condition, whereas "two" for a previously exposed concept with two different instances would be correct for subjects in the "different" condition. (Correct recognitions with incorrectly assigned frequencies were scored as incorrect.) Since our ultimate purpose is to utilize frequency judgment information to make inferences about the discrimination learning paradigm, it seened appropriate to restrict our attention here to this single measure which reflects subjects' accuracy in discriminating frequency.

The results for each experiment, expressed as percentages and broken down according to the type of stimulus materials (words or pictures) and list (same or different), are presented in Table 1. For each experiment, separate picture-word comparisons were made on each list type, in part to answer directly the major question of interest (viz, do picture-word differences obtain on a task involving conceptual frequency judgments?) and in part because of the differing variabilities associated with the two tasks (see Table 1). Each comparison was evaluated with $\alpha$

Table 1

Frequency Judgment Accuracy in Experiments 1 and 2 (Mean Percentage Correct)

\begin{tabular}{lcc} 
& \multicolumn{2}{c}{ Experiment } \\
& 1 & 2 \\
\hline Same List & & \\
Pictures & 74.9 & 83.5 \\
Words & 57.2 & 67.6 \\
& $(88.3)$ & $(71.0)$ \\
Different List & & \\
Pictures & 48.9 & 59.1 \\
Words & 44.5 & 52.1 \\
& $(134.7)$ & $(235.5)$ \\
\hline
\end{tabular}

Note-Pooled variances are in parentheses. 
$=.05$. Considering first the "same" list. in both experiments subjects in the picture condition were more accurate than were those in the word condition. $t(58)=7.31$ and $t(22)=4.62$. respectively. This finding corroborates the typically obtained pictureover-llord effect in frequency judgment tasks (cf. Ghatala \& Levin, 1974). When the "different" list data are considered, however, there is no evidence of the effect. $\mathrm{t}(58)=1.44$ and $\mathrm{t}(22)=1.12$, both ps $>.10$.

The data of Experiments I and II suggest that the usual advantage of pictures over words in frequency discrimination ("same" list) disappears when conceptual frequency judgments are required "different" list). Before regarding the lack of dilference in the latter condition as meaningful, however, we must rule out some alternative possibilities. In the first place, it could be argued that the nonsignificant differences were due to an effective "lloor" phenomenon which resulted from "different" subjects learning little or nothing during study list presentation. However, in view of the finding that the mininum level of performance for these subjects in the two experiments was $44.5 \%$ (see Table 1) -which represents a score well above $(p<.01)$ the computed "chance" levels $(24.7 \%$ or $36.4 \%$, assuming either a proportional or the optimal guessing strategy, respectively)-there is reason to discount this argument.

Il could also be argued that subjects viewing the "ditterent" list of words received an undue advantage wer subjects viewing pictures. in that, for them. the target category was explicitly pointed out with each instance (e.g., "cowboy boot," "rain boot"), whereas for subjects given the "different" list of pictures the target category had to be deduced. Indeed, certain pictures were not categorized in the intended manner and or could not be unambiguously associated with only one category by some subjects. Note, however, that neither is this explanation completely satisfactory. If "different" subjects given the word list did rely mainly on the second word in each pair, then their average performance should closely approximate that of "same" subjects given the word list, which, as may be seen in Table 1. it did not (a weighted across-experiment average of $46.7 \%$ correct in the "different"-word condition vs. $60.2 \%$ correct in the "same"-word condition). On the other hand, since there may be an element of truth to the above speculation, a third experiment was conducted with new materials. As will be seen, the new materials also permitted an assessment of item and category frequency judgments based on a common hist.

\section{EXPERIMENT III}

\section{Method}

Subjects and Design. The subjects were recruited for pay from the same pool as those serving in Experiment Il. Forty-eight subjects were equally divided between word and picture stimuli in either an item judgment or a category judgment task. All subjects were tested individually.

Materials and Procedure. Sixteen category labels, along with from one to five of the most common instances of each, were selected on the basis of the Battig and Montague (1969) category norms. Thus, taxonomic categories such as CLOTHING, FURNITURE, VEGETABLES, MUSICAL INSTRUMENTS, and the like were included. Slides consisted either of line drawings representing the category instances or of single words labeling them (e.g., "shirt." "dress").

The same study list (consisting of either words or pictures) was shown to subjects performing both tasks. The list contained 67 item presentations, with each of the 16 categories differing with respect to the number of instances representing it and the number of repetitions of each instance. For the study list, between one and four different instances combined with between one and four exposures of each instance (determined according to a prearranged format) were randomly allocated to the 16 categories. For example. the category TOOLS was represented by the single instance "hammer," which was presented only once. In contrast, the category TOYS contained the single instance "doll," which was presented four times: and the category VEGETABLES contained the instances "carrot," "bean." "peas." and "corn," which were presented one, one, one, and three times, respectively. As in the first two experiments, repetitions (of both items and same-category instances) occurred in different segments of the list.

Following study, the subjects performing the item-judgment task were presented with a 32 -item list (including 16 "zero" items from previously seen categories. e.g. " "celery" from the VEGETABLES category) and were asked to estimate how many times each instance had occurred on the study list. The subjects performing the category-judgment task (and who had been initially provided with a list of the category labels to be represented, as well as apprised of the nature of the list and their task) were presented with the 10 "zero" items and asked to estimate how many different instances from each category had been presented (ignoring repetitions of the same instances).

\section{Results}

In the item-judgment task, subjects viewing pictures were more accurate (an average of $86.7 \%$ correct, with a standard deviation of 9.2) than those viewing words $(\bar{X}=69.3 \%, \mathrm{SD}=10.5), \mathrm{t}(22)=$. 4.32 , thus confirming the previous results based on different materials. Also in support of the earlier findings, no difference between subjects shown pictures $(\bar{X}=57.8 \%, S D=19.4)$ and words $(X=$ $54.7 \%, \mathrm{SD}=17.9)$ was detected on the category-judgment task, $|\mathrm{t}|<1$. Once again, it cannot be argued that the latter task was simply too difficult, inasmuch as the mean performances more than doubled the computed "chance" level of $25 \%$. No other interesting results emerged when more tine-grained analyses of the data were conducted, i.e.. when the item vs. category repetition information was examined.

\section{GENERAL DISCUSSION}

The present research provides evidence that picture-word differences in subjective frequency accrual (see Ghatala \& Levin, 1974) may be restricted to nonconceptual tasks. In particular, the superiority enjoyed by pictures, relative to words, on an instance 
recognition task disappeared on one requiring instance classification. In the usual (nonconceptual) frequency judgment task, it may well be that (following Paivio. 1971) with pictures subjects are encoding unique perceptual information in addition to the verbal information elicited by the pictures labels, and that either or both of these codes may be re-evoked by the test stimuli.

In the conceptual frequency judgment task, however, subjects benefit not from the particular characteristics of stimuli, but rather from the generalized, more abstract features which form the basis for classification-abstractions which are probably most easily represented by a verbal code (but see Rosch, 1973). Thus, on such a task, pictures lose the advantage of perceptual uniqueness which operates in item recognition tasks. (Note, however. that the finding in the present experiments that pictures were no worse than words in the category judgment task suggests that subjects are able to switch their attention from the pictures' dominant perceptible properties to those more abstract or semantic features necessary for efficient conceptual frequency judgment performance.)

It should be mentioned here that, at the request of a reviewer, accuracy on the frequency judgment task has been analyzed separately by frequency level $(0,1$, 2. 3. 4). When this is done, decisions based on the overall accuracy measure remain the same for the 0 and 1 items. However, in Experiments $I$ and II (though not in Experiment III), an interesting finding emerges for the multiply occurring (2-4) items: picture subjects seem to be more accurate in comparison to word subjects on both the "same" and "different" lists. A possible (but yet to be tested systematically) explanation is that the narrowly defined categories of Experiments I and II furnish instances which are quite similar perceptually (e.g., two types of boot) in comparison to instances from the more broadly detined categories of Experiment III (e.g., a violin and a piano). Thus, in the former experiments, subjects may have utilized perceptual-feature information (as mentioned above for repeated pictures) when estimating the frequencies of multiply occurring "different" pictures.

At the same time, it is worth noting that the slight (though statistically nonsignificant) advantage of pictures over words in the conceptual tasks of the three experiments is in contrast with results of various concept acquisition and problem-solving studies, where the difference is frequently significant in the opposite direction (e.g., Deno, 1968; Runquist \& Hutt. 1961). However, in such studies, the nature of the task-and in particular the nature of the relationships among stimuli-is usually not made explicit to subjects, unlike the procedures adopted here (especially those for Experiments II and III). Extending this contrast in the other direction, it has been reported that pictures may even facilitate certain conceptual activities (e.g., prose comprehension) when the pictures are used in conjunction with verbal materials (see, for example, Bransford \& Johnson. 1973; Levin, in press). Thus, to find that pictures are not facilitative when used instead of verbal materials (as was the case here) is not incompatible with the prose comprehension findings (for supporting data, see Levin, 1973; and Rohwer \& Harris, 1975).

Finally, some extensions of the present results are clearly indicated. Would, for example, picture-word differences diminish on a discrimination learning task which capitalizes on the conceptual relationships among stimuli? Some preliminary work by Ingison and Levin (1975) may even serve to frame this question within a developmental perspective. Since young children are influenced relatively more by the dominant perceptible characteristics of pictures in comparison to older subjects. the largest picture-word difference reductions on such a task might be expected in younger populations. Indeed, the presently available empirical evidence (e.g., Hollenberg, 1970; Wohlwill, 1968) is certainly consistent with these speculations.

\section{REFERENCES}

Battig, W. F., \& Montague, W. E. Category norms for verbal items in 56 categories: A replication of the Connecticut category norms. Joumal of Experimental Psychology. 1969 , 80(3, Part 2)

Bransford. J. D.. \& Johnson. M. K. Considerations of some problems of comprehension. In W. G. Chase (Ed.), Visual intormation processing. New York: Academic Press. 1973.

DENo, S. L. Effects of words and pictures as stimuli in learning language equivalents. Journal of Educational Psychology. 1968. 59. 202.206.

Ekstrand. B. R.. Wallace. W. P., \& Underwood, B. J. A frequency theory of verbal-discrimination learning. Psychological Revien, 1966, 73, 566-578.

Ghatala. E. S., \& Levin, J. R. Developmental differences in frequency judgments of words and pictures. Journal of Experimental Child Psychology, 1973, 16. 495-507.

Ghatala, E. S., \& Levin, J. R. Discrimination learning as a function of differences in materials: A proposed explanation. Memory \& Cognition, 1974, 2. 395-400.

Ghatala, E. S., Levin, J. R., \& Wilder, L. Apparent frequency of words and pictures as a function of pronunciation and imagery. Journal of Verbal Learning and Verbal Behavior. 1973. 12, 85-90.

Hollenberg, C. K. Functions of visual imagery in the learning and concept formation of children. Child Development. 1970. 41. 1003-1015.

InGISON. L. J..\& LEVIN. J. R. The effect of children's spontaneous cognitive sets on discrimination learning. Journal of Experimental Child Psychology, 1975, 20, 59-65.

LEVIN. J. R. Inducing comprehension in poor readers: A test of a recent model. Journal of Educational Psychology. 1973. 65. 19.24 
LEVIN. J. R. Inducing comprehension in poor readers: A test of a recent model. Joumal of Educational Psychology, 1973 , 65. 19-24.

LEVIN. J. R. What have we learned about maximizing what children learn? In J. R. Levin \& V. L. Allen (Eds.), Cognitive learning in children: Theories and strategies. New York: Academic Press. in press.

Levin. J. R.. Ghatala. E. S., \& Wilder, L. Picture-word differences in discrimination learning: I. Apparent frequency manipulations. Journal of Experimental Psychology. 1974, 102. $691-695$.

PAIVIo, A. Imagen and verbal processes. New York: Holt, 1971.

Rohwer. W. D.. JR., \& Harris, W. J. Media effects on prose learning in two populations of children. Journal of Educational Psychology, 1975. 67, 651-657.

Rosch. E. On the internal structure of perceptual and semantic categories. In T. M. Moore (Ed.). Cognitive development and the acquisition of language. New York: Academic Press. 1973.
RowE. E. J. Discrimination learning of pictures and words: A replication of picture superiority. Joumal of Experimental Child Psychology, 1972, 14, 303-312.

Rowe, E. J.. \& Parvio, A. Discrimination learning of pictures and words. Psychonomic Science, 1971, 22, 87-88.

RunQuist, W. N., \& HutT, V. H. Verbal concept learning in high school students with pictorial and verbal representation of stimuli. Joumal of Educational Psychology, 1961, 52, 108-111.

WILDER, L.. \& LEVIN, J. R. A developmental study of pronouncing responses in the discrimination learning of words and pictures. Journal of Experimental Child Psychology. 1973, 15, 278-286.

WOHL WILL, J. F. Responses to class-inclusion questions for vetbally and pictorially presented items. Child Development, 1968. 39. 449-465.

(Received for publication March 18, 1975; revision received June 12,1975 .) 